\title{
Perception andCommunity Development among Youths in the Niger-Delta Region of Nigeria
}

\author{
Nwaiwu James Chima ${ }^{1}$, Hanina H. Hamsan ${ }^{2}$, Asnarulkhadi Abu Samah ${ }^{2}$ \\ Department of Community Development, Faculty of Human EcologyUniversity Putra Malaysia, \\ (UPM),Serdang, 43300, Selangor. Malaysia.
}

\begin{abstract}
This article discusses perception among youths based on the outcome results from a research conducted on Shell petroleum development company (SPDC) community development program for youths and business development in the Niger-Delta region of Nigeria. The study explores the relationship of perception to community development among youths (CDY) and the extent it can predict it. The study adopted a crosssectional survey by using self-administered questionnaire and simple random sampling as its sampling techniques. Sample size of 322 emerged from 2125 youths who benefited from SPDC's micro credit loan designed for youths and business development in the region based on the list provided by the micro-credit scheme for agricultural development (MISCAD). Instrument of assessment in this study was derived from literatures in line with indicators of measuring each of the construct variables as the test and retest prove the instrument to be valid and reliability since the cronbach's alpha of the constructs recording not less than 0.604. Descriptive, Pearson's correlation and Standard multiple regression analyses were used to break down the data. Findings from the outcome of the result show that there is strong relationship between perception and community development $(C D)$ among youths $(r=0.338, p=0.0001)$. Furthermore, the construct of interest which shapes perception was discovered as the major predictor of $C D$ among youth. The study recommends that increasing factor that spurs youth's interest should be encouraged in CD programs among youths.
\end{abstract}

Key words: Perception, Community Development and Youths

\section{Introduction}

The position of Shell Petroleum Development Company (SPDC) in Nigeria's economy has created room for higher expectation from them in the frontline of reducing high level of poverty and youths unemployment that has engulfed the people of Niger-Delta since decades due to problems emanating from disarticulation of economic activities caused by oil exploration business throughout the region. This disarticulation which has put the people of the Niger-Delta, who are predominantly fishermen and farmers out of job, has caused damaging fluctuation in the relationship between the company and their host communities. Youths are the most simulated in this disarticulation thus, their perception towards SPDC's activities and CDY programs may have contributed to continued insurgencies in the region. .

However, community development among youths (CDY) is a prominent issue of concern, which has been challenging to both government and private sector organizations since youths have the potential to create a serious problem that will cost the society if their problems are not addressed. Youths unemployment, militancy, armed robbery, kidnapping, drug abuse and host others which have linked to insurgencies that have polarized development and oil production activities in the Niger-Delta have not just cost Nigeria much as a nation but have continued to halt peace and development within the region.

Base on the above reasons, CDY has been placed as a process or approach which tries to develop competencies among youths to make them successful adults (National Collaboration for Youth, 2003; Center for Youth's Development and Policy Research, 1996; Youth Development Block Grant, 1995; Pittman, 1991). Community development among youths (CDY) therefore, has accommodated expected outcomes which youths must achieve and accomplished from CDY programs (National Collaboration for Youth, 2003). This becomes the basis in which the objective of this article to finding the relationship of perception to CDY and to which extent it can predict community development among youths. These expected outcomes have shaped CD program focus of enhancing stable environments where youths feel safe and perceive as theirs, while having access to basic care, supports and trainings. The opportunities provided under these programs is to sustain their relationships with adults as well as developing cultures of peer/ support, which has brought a shift paradigm from fixing youths problems to building and discovery of resilience that determines a healthy living standard among youths (Edelman, Gill, Comerford, Larson, and Hare, 2004).

Expected competencies and outcomes in this direction is determined by effective practical engagement of youths for a better adulthood which may overlap as a result of the needs of young people that revolve around the principal focus of CD target of building cognitive, social, civic, cultural, spiritual, vocational, physical, 
emotional, mental, personal, moral, or intellectual development among youths. It is on this basis that the definition of community development of youth has risen to accommodate youth leadership since issues of competency emerged in it focus.

Community development of youths, therefore, remains a process that prepares youths to meet the challenges of adolescence and stepping into adulthood through a progressively coordinated activity and experiences that help them to become socially, morally, emotionally, physically, and cognitively competent (National Collaboration for Youth, 2003). The investment model of youth's development gravitates to increase the quality and quantum of investment on youth development and also seek for proper youth involvement in development programs by promoting an approach to help in creating these competencies among young people. Forum for Youth Investment (2001) highlighted five developmental areas identified for an effective community development through a youths program which gears in areas of working, learning, thriving, connecting, and leading (Ferber, Pittman, and Marshall, 2002). Variation in community development of youth's program might differ in activities or plan, but the outcome remains constant and parallel within the context of target to be achieved.

\section{Focus area of Community Development among Youths}

\section{Literature review}

Community development of youths being an important area that guarantees sustainable development in every society revolves around three central developmental orbit of social, economic and psychology development. This three construct areas of CDY chair other areasof development such as political, cultural and physical development.

Social development focus to achieve optimal paradigmatic change in the socio-economic and psychological development within the society through utilization of both human and material resources available in a sustainable manner to meet the needs of individual members (Slaus\& Jacob, 2011).The critical consciousness which social development drive helps young people to build a constructive understanding that they can bring change to their lives and that of their communities by participating and perceiving community development of youths programs as an opportunity to affect changes to their present situation. Also, social development among youths helps in raising the consciousness of youths towards development (Abigail et al, 2011). This consciousness regulates perception, which shapes aggressive behaviors among youths. Consciousness can be raised through sports activities, musical concerts, rallies and some afterschool activities, which target to build competencies in the life of young people so that they will emerge as successful adults. Through social development, youths are spurred into collective action to speak out and effect changes in relation to issues that affect their lives; thus, becoming a tool for engaging and empowering of youths in communities and enhancing social change (Zakusi, Lombardo, and Skinner, 2002)

Recently, the World Bank identified three key principles that will be of focus if social development among youths is to be sustained. This predominantly accommodates the concept of, inclusion, cohesion and accountability (UNHCR, 2009). Manifestation of this concept in social development will structure programs to selvage individuals within the society from current experiences, which result or cause collective dislocation and also combat the factors that energize the manifestation of social discord, marginalization, depravity, and inequalities against the emerging leaders of our communities (Youths). Youths can surmount the difficulties that lie ahead of their developmental challenges by engaging in lucrative empowerment activities to build capacities and competency that grantees comfort and positive adult living (AYC, 2006). This eliminating barrier which hampers functional living standard due to poor management of human and material resources or lack of opportunities (Poveda, 2011). Youth economic development in this regard should be seen as actions and services that encourage youths with opportunities to marketable job skills, access to credit or fund, and entrepreneurship, which help in making them to be more productive to their businesses, families and their communities.

Action to enhance good entrepreneurship among youths can only guarantee success in CD programs if personal profiles and entrepreneurship traits possess by youths are properly harnessed and perceived as resources to profess favorable change in the lives of youths and that of their communities (Geraldine, Selvadurai, and Hamid, 2009, Inyang and Enuoh, 2009). Entrepreneurship traits such as motivation to achieve, determination, perseverance, explicit self-esteem, risk-taking attitude, initiative/responsibility, effort to seek out opportunity, forward thinking, goal orientation, creativity/innovation, honesty/integrity, sociability and locus of control over business are all seen as a trait of an individual that determined the level of CD in their lives. Furthermore, these personal profile and entrepreneur traits can be more efficient and effective when there is favorable innovation in terms of mechanism or technological invention that creates room for interest, good motive and positive attitude (Ommani, 2011). CD of youth's program also focused to achieve a balancecognitive state in the live of youths by ensuring pleasant physical and mental well-being, which guarantees productive that, makes them contributing adults. This brings psychological development among youths to 
focus towards enhancing safety, excellent health, and interactions through CDY programs designed for youths. It supports positive communications based on achieved intellectual and vocational competence that youth required to help themselves and their families while preserving resources beyond basic survival needs (NCFY, 2001)

\section{Perception verse CD among Youths}

Being aware of situations and able to interpreter information about happenings in our social environment is influenced by interest, motive and attitudes of those encountering the situation and as well as their needs (Adesope, Agumagu, Matthews-Njoku and Ukpongson, 2010). This perception forms the intuitive recognition, understanding or insight into the situation, item or persons. The distinctiveness, consistency of youth's voice in decision-making; access to leadership in line with facilitation, supports and viability of opportunities for youths shapes the level of perceptions, which will likely emanate from people interest, motive and attitude towards programs. This perception might in some cases create halo effects that may be selective, contrast and stereotyping; as it is shaped by the needs of people, and views of what they are capable of doing. Sanne's (2008) discovered that perceptions that place youths as at-risk and vulnerable are influencing their sense of control, resilience, capacity and ability to make use of available opportunities. He opined that youths detect themselves as being in certain circumstances in which they are recognized as risk to the society affect their interest to get involve in CD programs designed for them. This has made them to believe that community development of youths (CDY) programs are designed and assigned the responsibility to manage them to enhance competence that will make them useful adults as the progress into adulthood. Such design has made youths from their own understanding as people that need to be managed and not resources which the society required to flourish.

Vaughan (1999) provides insights into perceptual processes that can lead to misinterpretation of programs objective by young people, which might occur as a result of experience of similar moment, phenomenon or interaction, thus influencing youths response to contemporary situation that has led to the previous experience, phenomenon or interaction known and familiar with; for which emerged as the basis to interpret and establish responses. Silbery (2009) discovered that misperception of youth based on current situation and information that actively bury or discredit youth's resilience. Such a situation needs cautious and responsive interpretation since this has continued to affect youths perception towards programs meant for their development. This misperception has brought youths to the understanding that CDY programs are contingency measures designed by supporting agencies to arrest youths at-risk and vulnerable situation, which might have become sudden or disastrous to the society and can't be ignored or unattended to.

However, there is needed for supporting agencies to focus CDY program that does not perceive youths as problems but as a resource of value, which do not require any contingency in enhancing normal view and capacities among youths. Silbey (2009) investigation of perceptions draws a challenge between the process of CDY programs, which sees youths as at-risk and venerable group and the one that acknowledges youths as a resource that can be harnessed in achieving sustainable development among youths. The distinction between these two processes lies in the interest, motive and attitude of youths towards community development programs designed for them.

Perception has created a framework for the study of human personality; shaped by individual interest, attitude and motive as it hold the assumption that people are active organisms that can develop the tendencies toward growing, and integrating new experiences into a coherent sense of their interest towards a content area. Therefore, perceptions are driven by interest, which mastery's attendance, participation, goal achievement and learning (Harackiewicz and Durik, 2003; Ainley., Hidi., and Berndorff, 2002; Hoffmann, 2002; Koeller, Baumert, and Schnable, 2001; Harackiewicz, Barron, Tauer, Carter, and Elliot, 2000; Wade, Buxton, and Kelly, 1999). According to Beswick (2000) where there are lacked of curiosity or interest towards programs or a content area, there is a tendency that such program might be abandoned because people have a little interest. Approaches such as help, awakens, exciting and increased attention can promote interest (Cordova and Lepper, 1996). Furthermore, the way a program is introduced such as when they are presented in a manner that encourage individuals to focus on particular goal help in gaining interest and invariably from perceptions on the program as purposeful or not (Harackiewicz, Barron, and Elliot, 1998; Mitchell, 1993).

This development serves as a body monitors that initiated and creates a sub goal with spontaneous prioritization, which suppresses or transmits stimulation that triggers action to either develop interest or not concerning a situation (Solman, 1991). In this, perceptions are developed based on the individual motives about situation, which determines the evaluation of adoption, rejection, or deferring consideration, that shapes intentions about plans to achieve a particular motive, or reactivation of temporarily suspended motives that may have been abandoned or suspended due to fresh goals or action modification in the light of new information or goals. In other words, this will lead to changes in pattern, style, or method based on considerable factors such as satisfaction, frustrating, self-awareness or learning. As perception develops in this manner, the process of 
getting logical conclusions about things based on beliefs, value, feelings and disposition to act, and demonstrate an intuitive understanding of happening within our environment and course for actions becomes the emerging outcome which manifest in our attitude (Blankson, 2005).

In community development of youth's programs, supporting agency's responsiveness and involvement goes a long way in shaping rights attitudes of youths based upon their needs and active involvement. Hasle et al (2010) discovered that attitude manifestations in the lives of young people are always shaped by interaction of supporting agencies with them, which sometimes may be cynical or favorable. In such a situation, attribution of responsibility either for pessimistic or positive attitude are placed on supporting agencies such as program managers, family, schools, or the government, especially when youths build a negative attitude and wrong perceptions which affect their participation in community development programs designed to develop them. Attributions of responsibility are influenced by well-established beliefs about causes and effects involved were supporting agencies are being expected to take a certain action in address youths attitude towards community development of youths programs. If this is not checked, it will fragment development among them, as it creates rooms for uncertainties, thus limit efforts and commitment of supporting agencies (Fraser et al 2008).

\section{Methodology}

The design for this research is a cross-sectional survey study using a self-administered questionnaire to achieve the objective of the research. Sample sizes were drawn from population of 2125 beneficiaries of Shell Petroleum Development Company (SPDC) micro-credit loan for youths and business development in the NigerDelta region of Nigeria based on lists provided by the disbursing micro-credit institutions under the name Microcredit Scheme for Agricultural Development (MISCAD). It consists of youth's (male and female) age between 15 and 39 that are single, divorced, separated or widowed who has either pass through secondary, technical/vocational, diploma, bachelor or other academic qualifications, The location of this study was drawn from two local government's area each from Imo (Owerri and Uguta), Rivers (Port-Harcourt and Ikwerre) and Delta states (Aniocha south and Anoicha North) which are three out of the nine political Niger-Delta states. Through simple random sampling technique, the populations of 2125 beneficiaries which target to get 239 as the specimen expected to meet the statistical sample determination based on Bartlett, Kotrilik and Higgins (2001). Instrument of measurement for this study was derived from literatures in line with indicators of measuring each of the construct variables as the test and retest prove the instrument to be valid and reliable since the cronbach's alpha of the constructs recorded not less than 0.604. Descriptive, correctional and regression statistical analyses were used to break down the data to identify the level of perception and community development among youths while finding out the strength of their relationship and ability of each of the construct variables to single handedly predict community development among youths.

\section{Results and Discussion}

This study has a major objective of finding the relationship of perception and community development among youths. In achieving this, the level of perception and community development among participating youths were measured to find the level of variations using theconstructs variables. Also, the relationship of the variables were broadly investigated through a correlation analysis to find out how the variable relates with each other while trying to find out the predicting variable for community development among youths.

Levels of perception among youths are presented in table 1.1. The level of perception was measured with the construct variables of interest, motive and attitude. With the (Mean=3.64) and $(\mathrm{SD}=.413)$ the result shows that the perception level of respondents were moderate since the three construct that shape perception did not differ in the level that encompass the majority's perception towards the CD program. With interest having $(65.8 \%$,) motive $(73.3 \%)$, attitude $(69.3 \%)$ and the overall perception $(65.2 \%)$, it should be observed that the perception of respondents were not high nor low base on statistical evidence from the result. 


\section{Level of Community Development Among youths}

Table 1. Level of perception among youths.

\begin{tabular}{|c|c|c|c|c|c|c|}
\hline Variables & Range & Mean & (SD) & $\%$ male & \%female & \% Total \\
\hline Perception & & 3.64 & .413 & & & \\
\hline Low & $(1-3.23)$ & & & 9.3 & 7.1 & 16.4 \\
\hline Moderate & $(3.24-4,04)$ & & & 35.4 & 29.8 & 65.2 \\
\hline High & $(4.05-5)$ & & & 10.2 & 8.1 & 18.3 \\
\hline Interest & & 3.66 & .658 & & & \\
\hline Low & $(1-2.992)$ & & & 8.4 & 7.1 & 15.5 \\
\hline Moderate & $(2.923-4.327)$ & & & 36.0 & 29.8 & 65.8 \\
\hline High & $(4.238-5)$ & & & 10.6 & 8.1 & 18.7 \\
\hline Motive & & 3.66 & .645 & & & \\
\hline Low & $(1-3.015)$ & & & 10.2 & 6.5 & 16.8 \\
\hline Moderate & $(3.016-4.304)$ & & & 41.0 & 32.3 & 73.3 \\
\hline High & $(4.305-5)$ & & & 3.7 & 6.2 & 9.9 \\
\hline Attitude & & 3.69 & .646 & & & \\
\hline Low & $(1-3.044)$ & & & 8.7 & 6.2 & 14.9 \\
\hline Moderate & $(3.045-4.335)$ & & & 37.3 & 32.0 & 69.3 \\
\hline High & $(4.336-5)$ & & & 9.0 & 6.8 & 15.8 \\
\hline
\end{tabular}

Table 1 shows the level of $\mathrm{CD}$ among youths which were measured by the construct variables of social, economic and psychological development. With the (Mean=3.65) and (SD=.371) the results shows moderation with $74.1 \%$ while $13.8 \%$ are low and $12.2 \%$ of the respondent's CD levels are high. In the three constructs use to measuring variable for $\mathrm{CD}$ among youths, moderation level dominated in both social (74.1\%), economic (70.2\%) and psychological (73.6\%) as this shows that the level of CD among respondents were not high nor low base on statistical evidence from the result.

Table 2. Level of Development Among youths

\begin{tabular}{|c|c|c|c|c|c|c|}
\hline Variables & Range & Mean & (SD) & $\%$ male & \%female & \% Total \\
\hline Community Development & & 3.65 & .371 & & & \\
\hline Low & $(1-3.279)$ & & & 7.8 & 5.9 & 13.8 \\
\hline Moderate & $(3.280-4.020)$ & & & 41.6 & 32.5 & 74.1 \\
\hline High & $(4.021-5)$ & & & 5.9 & 6.2 & 12.2 \\
\hline Social Development & & 3.60 & .680 & & & \\
\hline Low & $(1-2.92)$ & & & 8.7 & 6.8 & 15.5 \\
\hline Moderate & $(2.93-4.27)$ & & & 37.6 & 32.6 & 70.2 \\
\hline High & $(4.28-5)$ & & & 8.7 & 5.6 & 14.3 \\
\hline Economic Development & & 3.67 & .604 & & & \\
\hline Low & $(1-3.066)$ & & & 6.5 & 5.9 & 12.4 \\
\hline Moderate & $(3.067-4.273)$ & & & 42.2 & 36.6 & 78.9 \\
\hline High & $(4.274-5)$ & & & 6.2 & 2.5 & 8.7 \\
\hline Psychological Development & & 3.68 & .645 & & & \\
\hline Low & $(1-3.035)$ & & & 10.6 & 5.9 & 16.5 \\
\hline Moderate & $(3.036-4.324)$ & & & 38.5 & 35.1 & 73.6 \\
\hline High & $(4.325-5)$ & & & 5.9 & 4.0 & 9.9 \\
\hline
\end{tabular}

Note : Scales Range $1=S D A$ to $5=S D A$

\section{Relationship of Perception and CD among Youths}

A Pearson correlation was use to determine the relationship of compounding variables of perception (Interest, Motive and Attitude) and CD of youths (Social, Economic and Psychological). The need for this statistical method is to determine the strength of relationship between perception and CD among youths. 


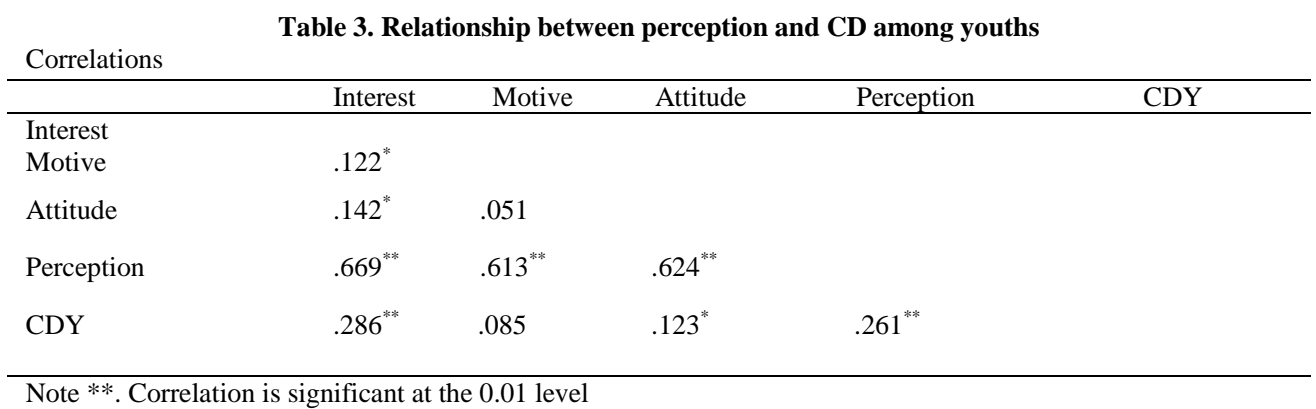

From the result presented in table 3, there are positive correlation between the two major variables of perception and CDY with $\mathrm{r}=0.338, \mathrm{n}=1, \mathrm{p}=0.0001$. A summary of results overall, shows that there is a positive correlation between perception and CDY as the correlated with increases in the levels. The relationship between perception and CDY, which correlate with co-efficiency of 0.338 shows that there is low linear correlation between the two variables, though the correlation are significant since $\mathrm{P}<0.001$.

\section{Predictor of CD among youth}

A standard multiple regression analysis was conducted to evaluate the strength of each construct variable of interest, motives and attitude (perception), in determining community development among youths as it access their significant rate of aggression.

Table 4. Regression model of community development Among youths

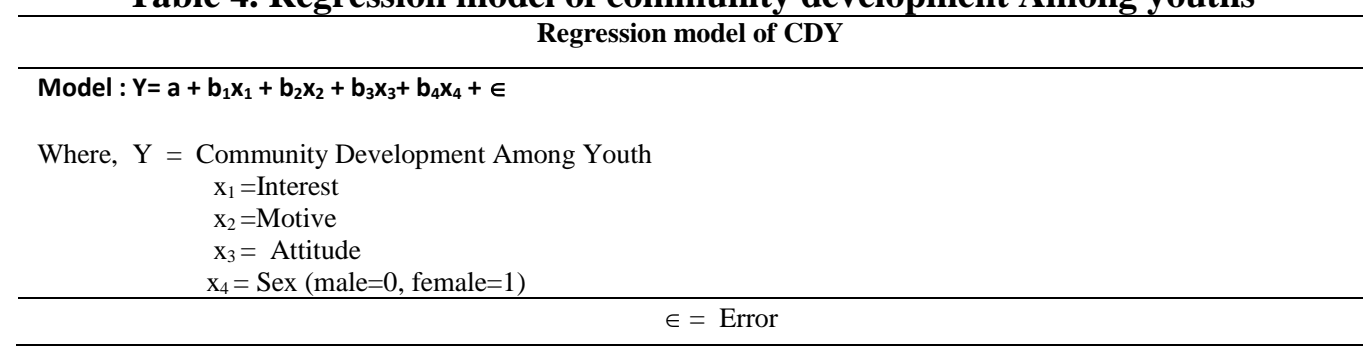

Table 5. Standard multiple regression that predict CD.

\begin{tabular}{lccc}
\hline \multicolumn{1}{c}{ Independent Variables } & Standard Beta, $\beta$ & t-value & sig \\
\hline & Community Development of Youth & $\mathrm{n}(322)$ \\
\hline Interest & .142 & 4.595 & .000 \\
Motive & .028 & .904 & .367 \\
Attitude & .040 & 1.289 & .198 \\
Sex (male=0, female=1) & .041 & -1.034 & .302 \\
& $\mathrm{R}^{2}=.105$ & & \\
& $\mathrm{~F}=6.176^{* * *}$ & & \\
\hline
\end{tabular}

Note: $\left(R^{2}=.105, F=6.176\right.$, Sig=000 $)$

The regression results in table 5 indicated $\left(\mathrm{R}^{2}=.105, \mathrm{~F}=6.176^{* * *}, \mathrm{p}=<.01\right)$. It was found that interest significantly predicted $\mathrm{CD}$ among youths. The analysis has show that interest can significantly predict community development among youths since it emerged as a strong predictor of CDY by holding significant of 0.0001 which is $\mathrm{p}<0.0001$.

\section{Discussion}

The moderate level of perception that dominated the respondents view on the CD program is an awaking call for improvement of those factors that can help in making CD programs attractive, which create feelings that controls attention, confidence, satisfaction, and curiosity that make CD programs to be relevance and valued by participants. Through this way, the motive of respondent over failure or rejection that cause lostof control, prestige, and integrity will become a hallmark of addressing intrinsic factors of youth's perception towards CD programs. Through this step, the competency expected as outcome from CD programs becomes reality (National Collaboration for Youth, 2003). Ideologically, the relationship between respondent's perceptions processes to CD programs focused on performance in terms of social, economic and psychological development, which supported the results as having strong relationships. Perception constructs such as interest 
to join, motive to accept or reject, and attitude to be determined or feel reluctant are seen as factors that shape the perception of an individual either to set quality standards, continual improvement, or venture goals. It paves ways to CD among youthsas it developed a sense of concern and curiosity which create room for cause of action(Hidi and Renninger; 2006). Though the work of (Hoffmann; 2002, Wade, Buxton \& Kelly; 1999) both point interest as a predicting variables for achievement which form the basis by which this research discovered it a s significantly predictor of $\mathrm{CD}$ among youths. The above has placed interest as an important concept to be harmonized not just in CD of youth's programs but to other sector of human endeavors such as politics, culture, entertainment, education and so on.

\section{Conclusion}

One of the major contingencies which ought to be a considerable factor for policy implementation in the outcomes of this research is that, there is a strong relationship between perception, and CD among youths based on the correlation analysis of this research result.Now that the relationship of perception and CD among youths has been sustained based on the research result, there is need for increment on those factors that will spur curiosity and make youths development programs to be attractive in order to increase youths involvement and participation in CD programs. Youths leadership, opportunity to contribute in decision-making, program design and the relationship that exist between youths and supporting agencies will become a paradigm that determines competencies which is expected outcome for community development of youths programs.

\section{Reference}

[1]. Adesope, O. M., Agumagu, A. C., Ukpongson, M. A., and Harcourt, P. (2010).Rural Youths Development Needs in the Niger Delta Area of Nigeria.Agricultural Economics, 32(1), 29-36.

[2]. Ainley, M., Hidi, S., and Berndorff, D. (2002).Interest, learning, and the psychological processes that mediate their relationship. Journal of Educational Psychology, 94(3), 545-561.

[3]. Bartlett, J. E., Kotrlik, J. W., and Higgins, C. C. (2001). Organizational Research: Determining Appropriate Sample Size in Survey Research. Spring, 19(1), 43-50.

[4]. Beswick, D. (2000).An Introduction to the Study of Curiosity. Retrieved from http://www.beswick.info/psychres/curiosityintro.htm.

[5]. Blankson., S. (2005). Attitude. Lulu Press.

[6]. Center for Youth Development and Policy Research (1996). Best practices in youth development: People, programs, organizations and communities. Unpublished manuscript.

[7]. Fraser, E. D. G., Termansen. M., Sun, N, D. Guan, E. Simelton, P. Dodds, K. Feng, and Y. Yu. (2008) Quantifying socio economic characteristics of drought sensitive regions: evidence from Chinese provincial agricultural data. ComptesRendus Geosciences 340:679-688.

[8]. Geraldine, Sivapalan, and Abdul Hamid (2009) Malay youth entrepreneurship in Malaysia: an empirical update. Geografia : Malaysian Journal of Society and Space, 5 (2). pp. 61-68.

[9]. Hoffman, JR., and Kang, J. (2002). Evaluation of a new anaerobic power testing system. Journal of Strength and Conditioning Research 16: 142-148.

[10]. Krapp, A. (2002a). An educational-psychological theory of interest and its relation to self determination theory. In E. Deci and R. Ryan (Eds.), The handbook of self-determination research (pp. 405-427). Rochester, NY: University of Rochester Press.

[11]. National Collaboration for Youth. (n.d).Definitions of youth development. RetrievedFeburary 2013 from www.nydic.org/nydic/devdef.html.

[12]. Pittman, K. (1991). Promoting youth development: Strengthening the role of youth serving and community organizations. Washington, D.C.: Academy for Educational Development

[13]. Poveda, A. C. (2007). Economic Development, Inequality and Poverty: An Analysis of Urban Violence in Colombia Economic Development, Inequality and Poverty: An Analysis of Urban Violence in Colombia. Development, (February 2013), 37-41

[14]. Sanne J, 'Framing risks in a safety-critical and hazardous job: risk-taking as responsibility in railway maintenance' (2008a) 11(5) Journal of Riskresearch, 645-657.

[15]. Šlaus, I., and Jacobs, G. (2011). Human Capital and Sustainability. Sustainability, 3(12), 97-154

[16]. Vaughan, D. (1999) “The dark side of organizations: Mistake, misconduct, and disaster," Annual Review of Sociology, 25: 271305 .

[17]. Wade, S. E., Buxton, W. M., and Kelly, M. (1999). Using think-alouds to examine reader-text interest. Reading Research Quarterly, 34, 194-216. 